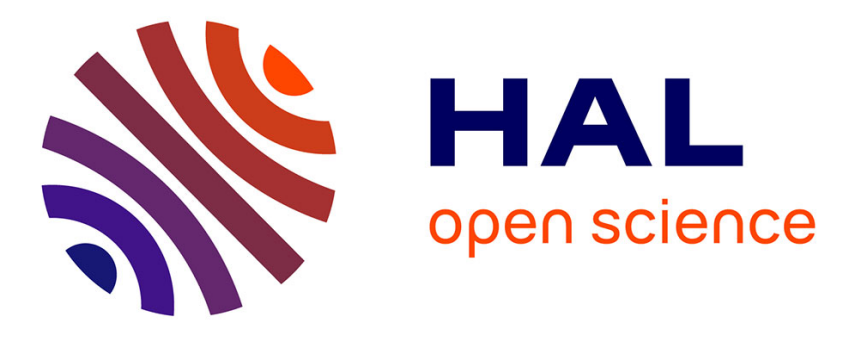

\title{
G-protein-coupled estrogen receptor GPR30 and tamoxifen resistance in breast cancer
}

\author{
Atanas Ignatov, Tanja Ignatov, Christine Weissenborn, Holm Eggemann, \\ Joachim Bischoff, Andrzej Semczuk, Albert Roessner, Serban Dan Costa, \\ Thomas Kalinski
}

\section{To cite this version:}

Atanas Ignatov, Tanja Ignatov, Christine Weissenborn, Holm Eggemann, Joachim Bischoff, et al.. G-protein-coupled estrogen receptor GPR30 and tamoxifen resistance in breast cancer. Breast Cancer Research and Treatment, 2011, 128 (2), pp.457-466. 10.1007/s10549-011-1584-1 . hal-00644275

\section{HAL Id: hal-00644275 https://hal.science/hal-00644275}

Submitted on 24 Nov 2011

HAL is a multi-disciplinary open access archive for the deposit and dissemination of scientific research documents, whether they are published or not. The documents may come from teaching and research institutions in France or abroad, or from public or private research centers.
L'archive ouverte pluridisciplinaire HAL, est destinée au dépôt et à la diffusion de documents scientifiques de niveau recherche, publiés ou non, émanant des établissements d'enseignement et de recherche français ou étrangers, des laboratoires publics ou privés. 


\title{
G-protein-coupled estrogen receptor GPR30 and tamoxifen resistance in breast cancer
}

\begin{abstract}
Atanas Ignatov ${ }^{1, a, b}$, Tanja Ignatov ${ }^{1, a}$, Christine Weißenborn ${ }^{1}$, Holm Eggemann ${ }^{1}$, Joachim Bischoff ${ }^{1}$, Andrzej Semczuk ${ }^{2}$, Albert Roessner ${ }^{3}$, Serban Dan Costa ${ }^{1, b}$, Thomas Kalinski ${ }^{3}$
\end{abstract}
${ }^{1}$ Department of Obstetrics and Gynecology, Otto-von-Guericke University, Magdeburg, Germany ${ }^{2} 2 n d$ Department of Gynecology, Lublin Medical University, Lublin, Poland.
${ }^{3}$ Department of Pathology, Otto-von-Guericke University, Magdeburg, Germany

${ }^{a}$ These two authors contributed equally to this work

${ }^{\mathrm{b} C}$ Corresponding author: Department of Obstetrics and Gynecology, Otto-von-Guericke University, G.Hauptmann Str. 35, 39108 Magdeburg, Germany; Phone: +493916717310; Fax: +493916717311.Email: serban-dan.costa@med.ovgu.de

\footnotetext{
${ }^{\mathrm{b}}$ Co-corresponding author: Department of Obstetrics and Gynecology, Otto-von-Guericke University, G.-Hauptmann Str. 35, 39108 Magdeburg, Germany; Phone: +493916717301; Fax: +493916717311.E-mail: atanas.ignatov@med.ovgu.de
}

Running title: GPR30 predicts tamoxifen treatment response in breast cancer Key words: GPR30, breast cancer, tamoxifen resistance, estrogen receptor 


\section{Abstract}

Recently we have shown that the new G-protein-coupled estrogen receptor GPR30 plays an important role in the development of tamoxifen resistance in vitro. This study was undertaken to evaluate the correlation between GPR30 and tamoxifen resistance in breast cancer patients. GPR30 protein expression was evaluated by immunohistochemical analysis in 323 patients with primary operable breast cancer. The association between GPR30 expression and tamoxifen resistance was confirmed in a second cohort of 103 patients treated only with tamoxifen. Additionally, we evaluated GPR30 expression in 33 primary tumors and in recurrent tumors from the same patients. GPR30 expression was detected in $56.7 \%$ of the breast cancer specimens investigated and it correlated with overexpression of HER$2(p=0.021)$, EGFR $(p=0.024)$ and lymph node status $(p=0.047)$. In a first cohort, survival analysis showed that GPR30 was negatively correlated with relapse-free survival (RFS) only in patients treated with tamoxifen (tamoxifen with or without chemotherapy). GPR30 expression was associated with shorter RFS (HR=1.768; $95 \% \mathrm{Cl}, 1.156-2.703 ; p=0.009)$. In a subset of patients treated only with tamoxifen, multivariate analysis revealed that GPR30 expression is an independent unfavorable factor for RFS, $(\mathrm{HR}=4.440 ; 95 \% \mathrm{Cl}, 1.408-13.997 ; p=0.011)$. In contrast, GPR30 tended to be a favorable factor regarding RFS in patients who did not receive tamoxifen. In 33 paired biopsies obtained before and after adjuvant therapy, GPR30 expression significantly increased only under tamoxifen treatment $(p=0.001)$. GPR30 expression in breast cancer independently predicts a poor RFS in patients treated with tamoxifen. 


\section{Introduction}

Tamoxifen is the most frequently used anti-hormonal drug for treatment of women with hormone-dependent breast cancer. Tamoxifen treatment is very effective in tumors expressing estrogen receptors (ER) and significantly reduces the mortality of breast cancer patients $[1 ; 2]$. Many patients with ER-positive breast cancer benefit from antihormonal treatment, but unfortunately, almost all patients eventually acquire resistance to these drugs. Several mechanisms underlying tamoxifen resistance have been proposed [3]. The lack of response or acquired resistance to antihormonal drugs remains a major clinical issue.

Recently, we have found that G-protein-coupled receptor GPR30 plays an important role in the development of tamoxifen resistance in breast cancer MCF-7 cell line [4]. GPR30 has been claimed to be a new membrane-bound estrogen receptor involved in the rapid nongenomic effects of estrogen [5]. It has been demonstrated that GPR30 mediates the proliferative effects of estrogen in breast cancer cells, endometrial cancer cells and ovarian cancer cells [6]. Moreover, ER antagonists such as tamoxifen and fulvestrant act as agonists for GPR30 and stimulate cell proliferation and growth [7-11] [6]. Long-term tamixifen treatment of MCF-7 cells increased the E2-stimulated up-regulation of GPR30 and its translocation from endoplasmatic reticulum to the cell surface [4]. GPR30 converts tamoxifen to a growth stimulator because its ability to act as an agonist for GPR30. In our experiments, EGFR transactivation via GPR30 was an important mechanism by which MCF-7 cells developed resistance to endocrine therapy [4]. It has been shown that crosstalk between steroid receptors and growth factor receptor pathways plays a key role in the development of resistance to endocrine therapy in breast cancer [12]. 
To verify these findings in breast cancer patients, we investigated the expression of GPR30 and EGFR in breast cancer tissue and compared it to established clinicopathological parameters and clinical outcome in terms of relapse free survival (RFS) and overall survival (OS). To investigate the expression of GPR30 during breast cancer progression, we compare it in 33 primary tumors and in their corresponding relapsed or metastasized tissues. 


\section{Materials and methods}

Immunohistochemistry

GPR30 expression was analyzed as previously described [13]. Sections of formalinfixed and paraffin-embedded breast cancer specimens or corresponding recurrent lesions $(3.0 \mu \mathrm{m}$ thick) were mounted on SuperFrost Plus glass slides (Menzel, Braunschweig, Germany) and dried overnight. A Benchmark XT (Ventana, Unterhaching, Germany) conducted the immunostaining. The slides were incubated with affinity-purified rabbit antibody against GPR30 (SP4677P; Acris antibodies, Herford, Germany) diluted 1:500 and against EGFR (Dako, Hamburg, Gerrmany) diluted 1:500 for $32 \mathrm{~min}$ at $37^{\circ} \mathrm{C}$, after antigen retrieval with Protease I (Ventana) for $10 \mathrm{~min}$. The reactions were visualized by DAB detection. The slides were counterstained with hematoxylin and cover slipped after being embedded in mounting medium.

\section{Evaluation of GPR30 staining results}

GPR30 expression was classified as already described [13], according to the following grading system: staining extensity was categorized as 0 (no positive cells), 1 ( $<10 \%$ positive cells), 2 ( $10-50 \%$ positive cells), or 3 ( $>50 \%$ positive cells), and staining intensity was categorized as 0 (negative), 1 (weak), 2 (moderate), or 3 (strong). The individual categories were multiplied to give a total immunohistochemical score (IHC). IHC score ranged between 0 and 9. The GPR30 cut-off was determined using the GPR30 expression in normal breast tissue surrounding the invasive breast cancer and is in agreement with the fact that cancerassociated fibroblasts show a robust functional GPR30 response [8].GPR30-positive 
expression was defined for tumors that showed an $\mathrm{IHC} \geq 3$. Representative examples of different GPR30 expression are shown in Figure 1. The specificity of the GPR30 peptide antibody was tested in cell lisates prepared from human embryonic kidney HEK-293 cells, human breast cancer MDA-MB231 and MCF-7 cells (Supplementary Fig. 1). GPR30 antibody detected a band with an estimated molecular weight of 42kDa only in MCF-7 cells. In HEK-293 and MDA-MB231 who do not express GPR30 [7;14;15] there was no detectable band. The transfection of MCF-7 cells with GPR30 anti-sense oligonucleotides as already described [4], reduced the expression of GPR30 significantly, resulting in a reduced intensity of the detected specific band (Supplementary Fig. 1). These data suggest that GPR30 antibody specifically detect the GPR30 protein.

\section{Evaluation of EGFR expression}

EGFR expression was determined as already described [16]. For assessment of EGFR expression, a following scoring system was used: 0 , no staining or unspecific staining; 1 , weak and incomplete expression of more than $10 \%$ of the tumor cells; 2 , moderate and complete staining of more than $10 \%$ and 3 , strong and complete staining of more than $10 \%$ of the cells. The staining was complete in a case of circumferential staining of the entire cell surface. The opposite was considered as incomplete. Representative examples of EGFR expression are shown in Figure $1 f, g, h$. 
The data of 384 patients with primary invasive breast cancer, who had been admitted to the Department of Obstetrics and Gynecology, Otto-von-Guericke University, Magdeburg, Germany from 1999 to 2005, were selected by retrospective analysis. Exclusion criteria included a previous history of adjuvant anti-hormonal or cytostatic therapy, primary non-operable tumor, no available archive material for detection of GPR30 expression and incomplete follow-up data. Three hundred twenty three patients were eligible for analysis. There was no significant difference between the final data set of 323 patients and the original group of 384 patients in terms of the patient and tumor characteristics. Patients underwent either modified radical mastectomy $(n=175,54.2 \%)$ or breast conservation surgery $(n=148,45.8 \%)$ in combination with axillary lymph node dissection. Adjuvant chemotherapy was given to $159(49.2 \%)$ patients mainly cyclophosphamide/methotrexate/5-fluoruracil (CMF) or epirubicin/cyclophosphamide (EC). Two hundred sixty eight $(82.9 \%)$ patients received adjuvant hormonal therapy. The median age at the time of primary diagnosis was 63 years (range 29-97 years), with 69 (21.4\%) pre-menopausal and $254(78.6 \%)$ post-menopausal. Outcome was measured as relapse-free survival (RFS) and overall survival (OS), according to the International Union Against Cancer (IUCC) criteria [17]. The follow-up was performed at the first recurrence of disease, patient death, or was based on the last available data in patient's registry. The median follow-up time of the study population was 51 months (range 1-134 months).

For validation of the results in the first cohort, we used a second cohort including 103 patients treated only with tamoxifen after surgery. The median age at the time of primary diagnosis for the second cohort was 67 years (range 37-97 years), 15 
(14.6\%) of whom were premenopausal and $88(85.4 \%)$ were postmenopausal. The median follow-up time of the study population was 51 months (range 2-118 months).

The main prognostic factors assessed in this study were patient age, menopausal status, estrogen receptor (ER), progesterone receptor (PR), HER-2 status, tumor size, tumor grading, histological type, and lymph node status. The tumors had been previously characterized immunocytochemically for their ER, PR and HER-2 status. Histological grade had also been assessed at the time of diagnosis from hematoxylin/eosin sections. The patient's characteristics are summarized in Table 1.

\section{Statistical analysis}

The statistical calculations were performed using SPSS Version 17.0 (SPSS, Chicago, IL, USA). An association between GPR30 expression and the tumor variables was evaluated using the $x^{2}$ test or Fisher's exact test. RFS and the OS were chosen as endpoints in this study. RFS analysis took into account those who died of breast cancer-specific death or had a recurrence of disease as a primary event. Patients who died of other causes or patients lacking follow-up data were censored. Survival was calculated using the Kaplan-Meier method. The equality of survival curves was tested by the log rank test. Univariate Cox proportional hazard regression analysis was used to identify significant prognostic factors. The prognostic significance was evaluated by multivariate analysis. The statistical analyses were two sided and $p$-values of $<0.05$ were considered statistically significant. The expression of GPR30 in primary tumors (PT's) and their corresponding recurrent lesions was analyzed using nonparametric paired analysis, and was performed with the Wilcoxon signed rank sum test. 


\section{Results}

GPR30 and EGFR protein expression

According to the inclusion criteria, from the 384 patients obtained from our database, 323 patients were eligible for analysis. Patients were considered positive for GPR30 if they had an IHC score of at least 2. GPR30 expression was observed predominantly on the plasma membrane and in the cell cytoplasm (Fig. 1). Figure 1 shows examples of GPR30 immunostaining of breast cancer tissue with negative staining (Fig. 1a), slightly positive staining (Fig. 1b), moderately positive (Fig. 1c) and strongly positive (Fig. 1d) cytoplasmic immunostaining. However, in 41 of 323 $(12.7 \%)$ cases, GPR30 was expressed also in the nucleus, as demonstrated in Figure 1e.

One hundred eighty three of the $323(56.7 \%)$ paraffin-embedded breast cancer specimens available for evaluation of GPR30 expression were classified as positive. All of the surrounding non-tumor mammary tissues included in the tissue specimens were GPR30-positive.

EGFR expression was evaluated in 292 cases. EGFR overexpression was observed in 46 of $292(15.8 \%)$ cases investigated (Table1). EGFR expression correlated with GPR30 expression ( $p=0.024$, Table 2$)$ and histological grading $(p=0.009)$, but did not correlate with HER-2 overexpression ( $p=0.447$, data not shown). EGFR overexpression was inversely correlated to the ER and PR status (data not shown). Moreover, EGFR status was a poor predictor for DFS and OS in the whole cohort of patients (data not shown). 


\section{GPR30 protein expression and tumor characteristics}

The results of GPR30 immunohistochemistry were compared with the prognostic parameters age, menopausal status, tumor size, metastases, nodal status, ER, PR, HER-2 and EGFR (Table 2). GPR30 immunostaining correlated significantly with HER-2 expression $(p=0.021)$, EGFR expression $(p=0.024)$ and lymph node status (0.047). About $70 \%$ of the tumors overexpressing HER-2 and EGFR demonstrated moderate or strong GPR30 expression (Table 2). Similarly, the GPR30-expression was higher in PR positive breast specimens, but without reaching a significant level. GPR30 expression was more often detected in cases of lymph node-negative tumors. There was no correlation between the expression of GPR30 and other tumor characteristics (Table 2).

\section{GPR30 and survival}

During the follow-up time (51 months median follow-up, range 1-134 months)., there were $118(36.5 \%)$ breast cancer relapses, 93 (78.8\%) of which occurred under endocrine therapy. There was no significant difference in OS between GPR30positive and -negative patients (data not shown). However, among all cases, the GPR30 positivity was associated with a significantly decreased RFS (Fig. 2a, $p=$ 0.024). Patients with GPR30 positive tumors receiving tamoxifen with or without chemotherapy, had poorer RFS than GPR30-negative patients. The 5-year RFS was 70.7\% for GPR30-negative patients and $59.6 \%$ for GPR30-positive patients $(p=0.030)$. Univariate analysis revealed that GPR30 expression was a prognostic factor for poor DFS (HR, 1.533; 95\% Cl, 1.051-2.235; $p=0.026$ ) (Table 3). After adjustment for menopausal status, tumor size, lymph node status, tumor grading, 
HER-2 status, EGFR status, ER status and PR status, multivariate analysis rendered GPR30 as an independent, unfavorable prognostic factor $(\mathrm{HR}, 1.768 ; 95 \% \mathrm{Cl}, 1.156-$ 2.703; $p=0.009$ ) (Table 3). Among the patients who did not receive tamoxifen as adjuvant therapy, GPR30 seemed to be a favorable factor of RFS (5-year RFS: $66.7 \%$ vs $74.2 \%$ for negative and positive cases, respectively) (Fig. 2b). For patients who did not received tamoxifen, GPR30 negativity was associated with poor RFS. However, this association was not significant $(P=0.204)$.

Kaplan-Meier survival analysis was subsequently done for GPR30-positive patients in relation to the tamoxifen treatment (Fig. 2c). The first group consisted of GPR30positive patients who received only tamoxifen, the second group of GPR30-positive patients treated with aromatase inhibitors or tamoxifen followed by an aromatase inhibitor. Tamoxifen treatment was associated with a significantly poorer RFS compared to the patients who received aromatase inhibitors ( $p=0.001$; Fig. $2 c)$. The 5 -year RFS $50.4 \%$ in patients receiving tamoxifen and $74.2 \%$ in patients receiving aromatase inhibitors or tamoxifen followed by an aromatase inhibitor respectively $(p=0.002)$. This finding shows that GPR30 expression is associated with poor RFS only in patients treated with tamoxifen.

To verify this observation, the influence of GPR30 on tamoxifen resistance was tested in a second cohort of 103 patients, who received only tamoxifen as adjuvant therapy. GPR30 expression was significantly associated with poorer RFS (Fig. 2d) with a 5-year RFS $58.5 \%$ vs. $86.8 \%$ for GPR30-positive and GPR30-negative patients, respectively $(p=0.002)$. Multivariate analysis revealed that GPR30 expression remains an independent unfavorable factor regarding RFS (HR, 4.440; $95 \% \mathrm{Cl}, 1.408-13.997, p=0.011)$ after adjustment for menopausal status, tumor size, lymph node status, tumor grading, PR status, HER-2 status, and EGFR status (Table 
4). These findings suggested again, that GPR30 is associated with poor RFS in patients treated with tamoxifen.

Change in GPR30 expression between PT and corresponding recurrent tissue In vitro we have recently found that GPR30 cell surface expression is increased after continuous tamoxifen treatment [4]. To verify these results in vivo we compared the GPR30 expression score between recurrent tissues and their corresponding PTs. Forty six patients with recurrent breast cancer were investigated. The GPR30 score was obtained in 33 of them. The sites of recurrence included 22 locoregional and 11 distant metastatic lesions. In these lesions, GPR30 expression was evaluated using the above described score and was compared with GPR30 expression in the primary tumor (PT). Twenty-one of these patients had been treated with tamoxifen, 7 with aromatase inhibitor and 5 had received chemotherapy only. GPR30 expression in PTs was determined before the adjuvant therapy. Representative examples of GPR30 expression in PT and corresponding metastases are shown in Figure 1i,j,k,l.

In 12 tumors having recurred during treatment with aromatase inhibitor and/or chemotherapy (Fig. 3a), GPR30 expression was increased in 8 (66.7\%) cases, decreased in $1(8.3 \%)$ case and it remained unchanged in $3(25 \%)$ cases ( $Z$ value, 1.658; $\mathrm{p}=0.114$ ). The mean $\mathrm{IHC}$ score in this group of patients was 2.67 in PT and 4.42 in the recurrent lesions ( $p=0.087$, Fig. 3b). However, in 21 tumors treated with tamoxifen, a significant increase in the GPR30 expression score was observed ( $Z$ value, $-3.212 ; p=0.001)$. Thus the IHC score had increased in 16 of $21(76.2 \%)$, was unchanged in 2 of 21 (9.5\%), and decreased in only 3 of 21 (14.3\%) (Fig. 3c). The 
mean IHC score for GPR30 was 3.57 and 6.33 in PT and the recurrent lesions, respectively ( $p=0.001$, Fig. $3 d)$. 


\section{Discussion}

In this study we investigated the expression of GPR30 in breast cancer and compared it with the RFS and OS in a cohort of 323 patients with invasive breast cancer. This study provides new insights into the mechanisms of acquired tamoxifen resistance and the pivotal role of GPR30.

GPR30-positive staining was observed in 183 of 323 (56.7\%) invasive breast cancers. In these series, GPR30 expression was associated with poorer RFS but not with OS. Interestingly, GPR30 was associated with a poorer RFS only in patients treated with tamoxifen in the adjuvant setting. In contrast, in a group of patients not having received tamoxifen after operation, GPR30 expression seemed to be even a favorable factor regarding RFS. However, this effect did not reach a significant level. These findings support our recent in vitro results, since GPR30 was associated with an increased resistance of MCF-7 breast cancer cells to tamoxifen [4]. Thus, GPR30 expression is associated with an increased risk of development of tamoxifen resistance.

In this study, we observed a significant correlation between GPR30 and HER-2 and EGFR, two members of a family of four structurally related tyrosine kinase receptors. Amplification of HER-2 and EGFR is one of the most common genetic alterations associated with breast cancer progression. About 70\% of the HER-2- and EGFRpositive tumors scored positive for GPR30, revealing a highly significant correlation between GPR30 and both receptors ( $p=0.021$ and $p=0.024$, respectively). It is in agreement with a very recent investigation of two independent research groups who found that GPR30 significantly correlates with HER-2 expression in breast cancer patients [18;19]. A correlation between GPR30 and EGFR expression has been reported for endometrial cancer patients [20]. This correlation may be of pivotal 
impact for tumor cells, since GPR30 can activate EGFR and make the tumor growth independent of ER [21]. Moreover, GPR30 expression is up-regulated in estrogen receptor-negative and estrogen receptor-positive cells by epidermal growth factor [22;23] and could be a good explanation of our finding that GPR30 expression correlates significantly with EGFR expression. In this context, the EGF-induced GPR30 up-regulation can be a milestone in GPR30- induced tamoxifen resistance.

The role of cross-talk between ER and growth factor receptors causing endocrine therapy resistance in breast cancer cells is well established [12]. An amplification and overexpression of HER-2 gene and increased protein expression occurs in about $12-25 \%$ of the human breast cancers [24-26]. However, the role of EGFR and HER-2 in the development of tamoxifen resistance in vivo is controversial. This association was very recently confirmed in large clinical trials [27-29], whereas in other studies, there was no significant correlation [30;31]. Multivariate analysis demonstrated that GPR30, HER-2 and EGFR are independent unfavorable predictors of RFS under tamoxifen therapy. GPR30 possibly supports the growth of tumors resistant towards tamoxifen by cross-talk with growth factor receptor signaling pathways, which has been observed in vitro [4], and will make the tumor growth independent of ER signaling [12]. Since tamoxifen acts as an agonist for GPR30 and leads to stimulation of cell proliferation and growth in many cell culture models [7-11] the growth of GPR30-positive breast cancer may be rather stimulated than inhibited by tamoxifen. The GPR30/growth factor receptor cross-talk is followed by phosphorylation of MAPK and Akt [4;7]. Thus, MAPK and Akt can further stimulate transcription of different genes (even ER), leading to cell growth proliferation. Then, again, the phosphorylated ER can further up-regulate GPR30, 
establishing a vicious circle [4]. Blocking of GPR30/EGFR signaling is a potential target to circumvent the tamoxifen resistance in breast cancer cells.

Prolonged tamoxifen treatment leads to an increased cell surface expression of GPR30 [4] and also to clonal selection of GPR30-positive tumor cells. We found that GPR30 expression is significantly increased in tamoxifen resistant tumor tissues. In contrast, GPR30 expression was not changed between the primary and recurrent tissue if aromatase inhibitor or chemotherapy was used. Since aromatase inhibitors and chemotherapy both reduce the amount of endogenous estrogen without altering GPR30 expression, we can assume that estrogen does not interfere with GPR30, while tamoxifen does. GPR30 expression may change under tamoxifen therapy. Moreover, GPR30-positive patients treated with aromatase inhibitors or tamoxifen followed by aromatase inhibitor demonstrated a longer RFS as compared with the GPR30-positive patients treated with tamoxifen alone. Therefore, GPR30-positivity might define a group of (postmenopausal) patients who benefit more from estrogen deprivation, in terms of aromatase inhibitor therapy, than from tamoxifen. The primary favorable effect of GPR30 expression on RFS in patients, who did not received tamoxifen, could be good explained by very recent results by Ariazi et coworkers who have find that GPR30 agonist inhibits proliferation of breast cancer cells [32].

In this study we did not observe a correlation between GPR30 and PR and ER, which is in contrast to other recent studies [18;19;33]. The authors have found a significant correlation between GPR30 and ER and PR. Indeed, in our population, the GPR30 immunostaining observed was stronger in ER- and PR-positive tumors, but this correlation did not reach significant levels. This supports the hypothesis that GPR30 and ER signaling are different and independent as already described in 
some cellular systems (for review [34]). The fact that 45 of 91 (49.5\%) of ERnegative tumors are GPR30-positive demonstrates again that GPR30 does not depend of ER [5;6;34]. GPR30 positivity in ER-negative tumors represents a new potential target for endocrine therapy.

In conclusion, this study indicated that GPR30 expression correlated significantly with EGFR and HER-2 expression, and was predictive for development of tamoxifen resistance. GPR30-positive tumors are less likely to benefit from tamoxifen therapy. Estrogen deprivation or blocking of GPR30/growth factor receptor cross-talk may be an alternative way to prevent development of tamoxifen resistance. A large number of patients treated with tamoxifen have to be further investigated in prospective clinical trials to confirm these findings.

Acknowledgments: We thank Carola Kügler und Claudia Miethke for excellent technical assistance.

Grant support: This work was supported by Deutsche Krebshilfe (Förderzeichen 108931).

Conflict of interest statement: The authors declare that there are no conflicts of interest. 


\section{References}

1. Early Breast Cancer Trialists' Collaborative Group (1998) Tamoxifen for early breast cancer: an overview of the randomised trials. Lancet 351:1451-1467

2. Powles TJ, Ashley S, Tidy A, Smith IE, and Dowsett M (2007) Twenty-year follow-up of the Royal Marsden randomized, double-blinded tamoxifen breast cancer prevention trial. J Natl Cancer Inst 99:283-290

3. Hutcheson IR, Knowlden JM, Madden TA, Barrow D, Gee JM, Wakeling AE, and Nicholson RI (2003) Oestrogen receptor-mediated modulation of the EGFR/MAPK pathway in tamoxifen-resistant MCF-7 cells. Breast Cancer Res Treat 81:81-93

4. Ignatov A, Ignatov T, Roessner A, Costa SD, and Kalinski T (2009) Role of GPR30 in the mechanisms of tamoxifen resistance in breast cancer MCF-7 cells. Breast Cancer Res Treat 123:87-96

5. Rae JM and Johnson MD (2005) What does an orphan G-protein-coupled receptor have to do with estrogen? Breast Cancer Res 7:243-244

6. Prossnitz ER, Oprea TI, Sklar LA, and Arterburn JB (2008) The ins and outs of GPR30: a transmembrane estrogen receptor. J Steroid Biochem Mol Biol 109:350-353

7. Filardo EJ, Quinn JA, Bland KI, and Frackelton AR, Jr. (2000) Estrogeninduced activation of Erk-1 and Erk-2 requires the G protein-coupled receptor homolog, GPR30, and occurs via trans-activation of the epidermal growth factor receptor through release of HB-EGF. Mol Endocrinol 14:1649-1660 
8. Pandey DP, Lappano R, Albanito L, Madeo A, Maggiolini M, and Picard D (2009) Estrogenic GPR30 signalling induces proliferation and migration of breast cancer cells through CTGF. EMBO J 28:523-532

9. Thomas P, Pang Y, Filardo EJ, and Dong $\mathrm{J}$ (2005) Identity of an estrogen membrane receptor coupled to a $G$ protein in human breast cancer cells. Endocrinology 146:624-632

10. Vivacqua A, Bonofiglio D, Recchia AG, Musti AM, Picard D, Ando S, and Maggiolini M (2006) The G protein-coupled receptor GPR30 mediates the proliferative effects induced by 17beta-estradiol and hydroxytamoxifen in endometrial cancer cells. Mol .Endocrinol 20:631-646

11. Vivacqua A, Bonofiglio D, Albanito L, Madeo A, Rago V, Carpino A, Musti AM, Picard D, Ando S, and Maggiolini M (2006) 17beta-estradiol, genistein, and 4hydroxytamoxifen induce the proliferation of thyroid cancer cells through the $\mathrm{g}$ protein-coupled receptor GPR30. Mol Pharmacol 70:1414-1423

12. Osborne CK, Shou J, Massarweh S, and Schiff R (2005) Crosstalk between estrogen receptor and growth factor receptor pathways as a cause for endocrine therapy resistance in breast cancer. Clin Cancer Res 11:865s870 s

13. Ignatov $\mathrm{T}$, Eggemann $\mathrm{H}$, Semczuk A, Smith B, Bischoff J, Roessner A, Costa SD, Kalinski T, and Ignatov A (2010) Role of GPR30 in endometrial pathology after tamoxifen for breast cancer. Am J Obstet Gynecol 203:595-16 
14. Filardo E, Quinn J, Pang Y, Graeber C, Shaw S, Dong J, and Thomas P (2007) Activation of the novel estrogen receptor G protein-coupled receptor 30 (GPR30) at the plasma membrane. Endocrinology 148:3236-3245

15. Kang L, Zhang X, Xie Y, Tu Y, Wang D, Liu Z, and Wang ZY (2010) Involvement of estrogen receptor variant ER-alpha36, not GPR30, in nongenomic estrogen signaling. Mol Endocrinol 24:709-721

16. Giltnane JM, Ryden L, Cregger M, Bendahl PO, Jirstrom K, and Rimm DL (2007) Quantitative measurement of epidermal growth factor receptor is a negative predictive factor for tamoxifen response in hormone receptor positive premenopausal breast cancer. J Clin Oncol 25:3007-3014

17. Hayward JL, Carbone PP, Heusen JC, Kumaoka S, Segaloff A, and Rubens $\mathrm{RD}$ (1977) Assessment of response to therapy in advanced breast cancer. $\mathrm{Br}$ J Cancer 35:292-298

18. Filardo EJ, Graeber CT, Quinn JA, Resnick MB, Giri D, DeLellis RA, Steinhoff MM, and Sabo E (2006) Distribution of GPR30, a seven membrane-spanning estrogen receptor, in primary breast cancer and its association with clinicopathologic determinants of tumor progression. Clin Cancer Res $12: 6359-6366$

19. Liu Q, Li JG, Zheng XY, Jin F, and Dong HT (2009) Expression of CD133, PAX2, ESA, and GPR30 in invasive ductal breast carcinomas. Chin Med J (Engl.) 122:2763-2769 
20. Smith HO, Leslie KK, Singh M, Qualls CR, Revankar CM, Joste NE, and Prossnitz ER (2007) GPR30: a novel indicator of poor survival for endometrial carcinoma. Am J Obstet Gynecol 196:386-389

21. Filardo EJ, Quinn JA, and Sabo E (2008) Association of the membrane estrogen receptor, GPR30, with breast tumor metastasis and transactivation of the epidermal growth factor receptor. Steroids $73: 870-873$

22. Albanito L, Sisci D, Aquila S, Brunelli E, Vivacqua A, Madeo A, Lappano R, Pandey DP, Picard D, Mauro L, Ando S, and Maggiolini M (2008) Epidermal growth factor induces $\mathrm{G}$ protein-coupled receptor 30 expression in estrogen receptor-negative breast cancer cells. Endocrinology 149:3799-3808

23. Vivacqua A, Lappano R, De Marco P, Sisci D, Aquila S, De Amicis F, Fuqua SA, Ando S, and Maggiolini M (2009) G Protein-Coupled Receptor 30 Expression Is Up-Regulated by EGF and TGF\{alpha\} in Estrogen Receptor \{alpha\}-Positive Cancer Cells. Mol Endocrinol 23:1815-1826

24. King CR, Kraus MH, and Aaronson SA (1985) Amplification of a novel verbB-related gene in a human mammary carcinoma. Science 229:974-976

25. Slamon DJ, Clark GM, Wong SG, Levin WJ, Ullrich A, and McGuire WL (1987) Human breast cancer: correlation of relapse and survival with amplification of the HER-2/neu oncogene. Science 235:177-182

26. van de Vijver MJ, Mooi WJ, Wisman P, Peterse JL, and Nusse R (1988) Immunohistochemical detection of the neu protein in tissue sections of human breast tumors with amplified neu DNA. Oncogene 2:175-178 
27. Borg A, Baldetorp B, Ferno M, Killander D, Olsson H, Ryden S, and Sigurdsson H (1994) ERBB2 amplification is associated with tamoxifen resistance in steroid-receptor positive breast cancer. Cancer Lett 81:137-144

28. Ellis MJ, Coop A, Singh B, Mauriac L, Llombert-Cussac A, Janicke F, Miller WR, Evans DB, Dugan M, Brady C, Quebe-Fehling E, and Borgs M (2001) Letrozole is more effective neoadjuvant endocrine therapy than tamoxifen for ErbB-1- and/or ErbB-2-positive, estrogen receptor-positive primary breast cancer: evidence from a phase III randomized trial. J Clin Oncol 19:38083816

29. Houston SJ, Plunkett TA, Barnes DM, Smith P, Rubens RD, and Miles DW, Overexpression of c-erbB2 is an independent marker of resistance to endocrine therapy in advanced breast cancer. $\mathrm{Br} \mathrm{J}$ Cancer 79:1220-1226, 1999.

30. Knoop AS, Bentzen SM, Nielsen MM, Rasmussen BB, and Rose C (2001) Value of epidermal growth factor receptor, HER2, p53, and steroid receptors in predicting the efficacy of tamoxifen in high-risk postmenopausal breast cancer patients. J Clin Oncol 19:3376-3384

31. Soubeyran I, Quenel N, Mauriac L, Durand M, Bonichon F, and Coindre J-M (1996) Variation of hormonal receptor, pS2, c-erbB-2 and GSTpi contents in breast carcinomas under tamoxifen: a study of 74 cases. $\mathrm{Br} \mathrm{J}$ Cancer 73:735743

32. Ariazi EA, Brailoiu E, Yerrum S, Shupp HA, Slifker MJ, Cunliffe HE, Black MA, Donato AL, Arterburn JB, Oprea TI, Prossnitz ER, Dun NJ, and Jordan VC 
(2010) The G protein-coupled receptor GPR30 inhibits proliferation of estrogen receptor-positive breast cancer cells. Cancer Res 70:1184-1194

33. Kuo WH, Chang LY, Liu DL, Hwa HL, Lin JJ, Lee PH, Chen CN, Lien HC, Yuan RH, Shun CT, Chang KJ, and Hsieh FJ (2007) The interactions between GPR30 and the major biomarkers in infiltrating ductal carcinoma of the breast in an Asian population. Taiwan J Obstet Gynecol 46:135-145

34. Levin ER (2009) G protein-coupled receptor 30: estrogen receptor or collaborator? Endocrinology 150:1563-1565 
Figure legends:

Fig. 1 Paraffin-embedded breast tumor tissue immunostained with GPR30 or EGFR antibodies. GPR30 immunostaining of breast cancer tissue showing negative (a), weak (b), moderate (c) or strong positive cytoplasmic staining (d). e) GPR30 positive staining in cytoplasm and nucleus. EGFR staining of breast cancer tissue showing no staining (f), moderate and complete staining (g) and strong and complete staining (h). GPR30 weak staining in primary breast cancer (i) and corresponding skin metastasis showing strong GPR30 staining (j). k) Example of GPR30 moderate staining in PT and GPR30 strong expression in the corresponding liver metastasis after tamoxifen (I). Original magnification: x 200.

Fig. 2 Kaplan-Meier plots for relapse-free survival according to the GPR30 status. a) Relapse-free survival in the whole patient group. b) Relapse-free survival in the patient's cohort treated with aromatase inhibitors or tamoxifen followed by aromatase inhibitors. c) Relapse-free survival in GPR30 positive patient treated with tamoxifen only (TAM) or aromatase inhibitor and tamoxifen switched to aromatase inhibitor (Al/Switch). d) Relapse-free survival in the patient's cohort treated with tamoxifen only. The log rank test was used to calculate the $p$-value.

Fig. 3 GPR30 expression in 33 matched tissue from primary tumor (PT) and corresponding relapsed/metastasized tissue (Met). Paired change (a) and quantitative (b) comparison in GPR30 expression between PT and Met in patients who did not receive tamoxifen therapy; Matched change (c) and quantitative (d) comparison in GPR30 expression between PT and Met under tamoxifen therapy.

Table 1. Patient's charachteristics. 


\begin{tabular}{|c|c|c|c|c|}
\hline \multirow[b]{2}{*}{ Characteristic } & \multicolumn{2}{|c|}{ Cohort 1} & \multicolumn{2}{|c|}{ Cohort 2} \\
\hline & $\mathrm{N}$ & $\%$ & $\mathrm{~N}$ & $\%$ \\
\hline Total & \multicolumn{2}{|l|}{323} & \multicolumn{2}{|l|}{103} \\
\hline Age (range) & \multicolumn{2}{|c|}{$63(29-97)$} & \multicolumn{2}{|c|}{$67(37-97)$} \\
\hline \multicolumn{5}{|l|}{ GPR30 } \\
\hline negative & 140 & 43.3 & 38 & 36.9 \\
\hline positive & 183 & 56.7 & 65 & 63.1 \\
\hline \multicolumn{5}{|l|}{ Menopausal status } \\
\hline premenopausal & 69 & 21.4 & 15 & 14.6 \\
\hline postmenopausal & 254 & 78.6 & 88 & 85.4 \\
\hline \multicolumn{5}{|l|}{ Tumor size, cm } \\
\hline$\leq 2$ & 167 & 51.7 & 73 & 70.9 \\
\hline$>2$ & 156 & 48.3 & 30 & 29.1 \\
\hline \multicolumn{5}{|l|}{ Lymph node status } \\
\hline negative & 205 & 63.5 & 92 & 89.3 \\
\hline positive & 118 & 36.5 & 11 & 10.7 \\
\hline \multicolumn{5}{|l|}{ Histological typ } \\
\hline Ductal & 254 & 78.6 & 77 & 74.8 \\
\hline Lobular & 55 & 17.0 & 19 & 18.4 \\
\hline Other & 14 & 4.3 & 7 & 6.8 \\
\hline \multicolumn{5}{|l|}{ Histologic grade } \\
\hline 1 & 33 & 10.2 & 20 & 19.4 \\
\hline 2 & 182 & 56.3 & 66 & 64.1 \\
\hline 3 & 108 & 33.4 & 17 & 16.5 \\
\hline \multicolumn{5}{|l|}{ ER status } \\
\hline negative & 91 & 28.2 & 13 & 12.6 \\
\hline positive & 232 & 71.8 & 92 & 87.4 \\
\hline \multicolumn{5}{|l|}{ PR status } \\
\hline negative & 150 & 46.4 & 34 & 33.0 \\
\hline positive & 173 & 53.6 & 69 & 67.0 \\
\hline \multicolumn{5}{|l|}{ HER-2 status } \\
\hline negative & 252 & 78.0 & 88 & 85.4 \\
\hline positive & 71 & 22.0 & 15 & 14.6 \\
\hline \multicolumn{5}{|l|}{ EGFR status } \\
\hline negative & 246 & 76.2 & 73 & 70.9 \\
\hline positive & 46 & 14.2 & 10 & 9.7 \\
\hline missing & 31 & 9.6 & 20 & 80.6 \\
\hline
\end{tabular}




\begin{tabular}{lcccc} 
Operative therapy & & & & \\
Breast concerving & 148 & 45.8 & 51 & 49.5 \\
Mastectomy & 175 & 54.2 & 52 & 50.5 \\
& & & & \\
Adjuvant therapy & & & & \\
Chemotherapy & 159 & 49.2 & 0 & \\
Tamoxifen & 191 & 59.1 & 103 & \\
Aromatase inhib. & 77 & 23.8 & 0 & \\
No treatment & 6 & 1.9 & 0 & 100 \\
& & & & \\
\hline
\end{tabular}

Table 2. GPR30 and tumor characteristics.

\begin{tabular}{|c|c|c|c|c|c|c|}
\hline \multirow[b]{3}{*}{ Characteristic } & \multirow[b]{3}{*}{$\mathrm{N}$ of Patients } & \multicolumn{4}{|c|}{ GPR30 } & \multirow[b]{3}{*}{$\mathrm{p}$} \\
\hline & & \multicolumn{2}{|c|}{ negative } & \multicolumn{2}{|c|}{ positive } & \\
\hline & & $\mathrm{N}$ & $\%$ & $\mathrm{~N}$ & $\%$ & \\
\hline Total & 323 & 140 & 43.3 & 183 & 56.7 & \\
\hline Age (range) & & \multicolumn{2}{|c|}{$64(33-87)$} & \multicolumn{2}{|c|}{$62(29-97)$} & 0.587 \\
\hline \multicolumn{7}{|l|}{ Menopausal status } \\
\hline premenopausal & 69 & 27 & 39.1 & 42 & 60.9 & \\
\hline postmenopausal & 254 & 113 & 44.5 & 141 & 55.5 & 0.494 \\
\hline \multicolumn{7}{|l|}{ Tumor size, $\mathrm{cm}$} \\
\hline$\leq 2$ & 167 & 68 & 40.7 & 99 & 59.3 & \\
\hline$>2$ & 156 & 72 & 46.2 & 84 & 53.8 & 0.369 \\
\hline \multicolumn{7}{|l|}{ Lymph node status } \\
\hline negative & 205 & 80 & 39.0 & 125 & 61.0 & \\
\hline positive & 118 & 60 & 50.8 & 58 & 49.2 & 0.047 \\
\hline \multicolumn{7}{|l|}{ Histological typ } \\
\hline Ductal & 254 & 116 & 45.7 & 138 & 54.3 & \\
\hline Lobular & 55 & 17 & 30.9 & 38 & 69.1 & \\
\hline Other & 14 & 7 & 50.0 & 7 & 50.0 & 0.118 \\
\hline \multicolumn{7}{|l|}{ Histologic grade } \\
\hline 1 & 33 & 14 & 42.4 & 19 & 57.6 & \\
\hline 2 & 182 & 71 & 39.0 & 111 & 61.0 & \\
\hline 3 & 108 & 55 & 50.9 & 53 & 49.1 & 0.140 \\
\hline
\end{tabular}




\begin{tabular}{|c|c|c|c|c|c|c|}
\hline \multicolumn{7}{|l|}{ ER status } \\
\hline negative & 91 & 46 & 50.5 & 45 & 49.5 & \\
\hline positive & 232 & 94 & 40.5 & 138 & 59.5 & 0.107 \\
\hline \multicolumn{7}{|l|}{ PR status } \\
\hline negative & 150 & 74 & 49.3 & 76 & 50.7 & \\
\hline positive & 173 & 66 & 38.2 & 107 & 61.8 & 0.055 \\
\hline \multicolumn{7}{|c|}{ HER-2 status } \\
\hline negative & 252 & 118 & 46.8 & 134 & 53.2 & \\
\hline positive & 71 & 22 & 31.0 & 49 & 69.0 & 0.021 \\
\hline \multicolumn{7}{|c|}{ EGFR status } \\
\hline negative & 246 & 120 & 48.8 & 126 & 51.2 & \\
\hline positive & 46 & 14 & 30.4 & 32 & 69.6 & 0.024 \\
\hline
\end{tabular}

Table 3. Uni- and multivariate analysis regarding RFS.

\begin{tabular}{|c|c|c|c|c|c|c|}
\hline \multirow[b]{2}{*}{ Prognostic factor } & \multicolumn{3}{|c|}{ Univariate analysis } & \multicolumn{3}{|c|}{ Multivariate analysis } \\
\hline & $\mathrm{HR}$ & $95 \% \mathrm{Cl}$ & $\mathrm{p}$ & $\mathrm{HR}$ & $95 \% \mathrm{Cl}$ & $\mathrm{p}$ \\
\hline \multicolumn{7}{|l|}{$\begin{array}{l}\text { GPR30 } \\
\text { positive vs }\end{array}$} \\
\hline & 1.533 & $1.051-2.235$ & 0.026 & 1.768 & $1.156-2.703$ & 0.009 \\
\hline \multicolumn{7}{|l|}{ Menopausal status } \\
\hline pre vs post & 0.714 & $0.476-1.072$ & 0.104 & 0.836 & $0.527-1.324$ & 0.444 \\
\hline \multicolumn{7}{|l|}{ Tumor size } \\
\hline$>2$ vs $\leq 2 \mathrm{~cm}$ & 2.224 & $1.528-3.238$ & $<0.0001$ & 1.790 & $1.172-2.734$ & 0.007 \\
\hline \multicolumn{7}{|l|}{$\begin{array}{l}\text { Lymph node status } \\
\text { positive vs }\end{array}$} \\
\hline negative & 2.048 & $1.427-2.939$ & $<0.0001$ & 1.974 & $1.308-2.979$ & 0.001 \\
\hline \multicolumn{7}{|l|}{ Histologic grade } \\
\hline 3 vs 1 and 2 & 1.950 & $1.356-2.803$ & $<0.0001$ & 1.659 & $1.062-2.591$ & 0.026 \\
\hline \multicolumn{7}{|l|}{$\begin{array}{l}\text { PR status } \\
\text { positive vs }\end{array}$} \\
\hline negative & 0.622 & $0.433-0.894$ & 0.010 & 0.795 & $0.497-1.270$ & 0.337 \\
\hline $\begin{array}{l}\text { ER status } \\
\text { positive vs }\end{array}$ & 0.599 & $0.410-0.873$ & 0.008 & 0.981 & $0.593-1.623$ & 0.941 \\
\hline
\end{tabular}


negative

HER-2 status

positive vs

negative

$\begin{array}{llllll}1.888 & 1.275-2.795 & 0.002 & 1.566 & 1.014-2.417 & 0.043\end{array}$

EGFR status

positive vs

negative

$27.10 .1905 \quad 1.360-3.324$

0.001

$1.506 \quad 0.944-2.402 \quad 0.86$

Table 4. Multivariate analysis of RFS in cohort 2.

\begin{tabular}{|c|c|c|c|}
\hline Fatcor & HR & $95 \% \mathrm{Cl}$ & $p$ \\
\hline \multicolumn{4}{|l|}{ GPR30 } \\
\hline positive vs negative & 4.440 & $1.408-13.997$ & 0.011 \\
\hline \multicolumn{4}{|l|}{ Menopausal status } \\
\hline pre vs post & 1.749 & $0.373-8.195$ & 0.478 \\
\hline \multicolumn{4}{|l|}{ Tumor size } \\
\hline$>2$ vs $\leq 2 \mathrm{~cm}$ & 1.323 & 0.548-3.196 & 0.534 \\
\hline \multicolumn{4}{|l|}{ Lymph node status } \\
\hline positive vs negative & 0.787 & $0.251-2.472$ & 0.682 \\
\hline \multicolumn{4}{|l|}{ Histologic grade } \\
\hline 3 vs 1 and 2 & 2.779 & $0.943-8.193$ & 0.064 \\
\hline \multicolumn{4}{|l|}{ PR status } \\
\hline negative vs positive & 1.319 & $0.537-3.243$ & 0.546 \\
\hline \multicolumn{4}{|l|}{ HER-2 status } \\
\hline positive vs negative & 3.120 & $1.097-8.873$ & 0.033 \\
\hline \multicolumn{4}{|l|}{ EGFR status } \\
\hline positive vs negative & 4.201 & $1.373-12.853$ & 0.012 \\
\hline
\end{tabular}


- $29-$ 
Figure 1

Cliprfigeqo download Figure: Fig1.ppt
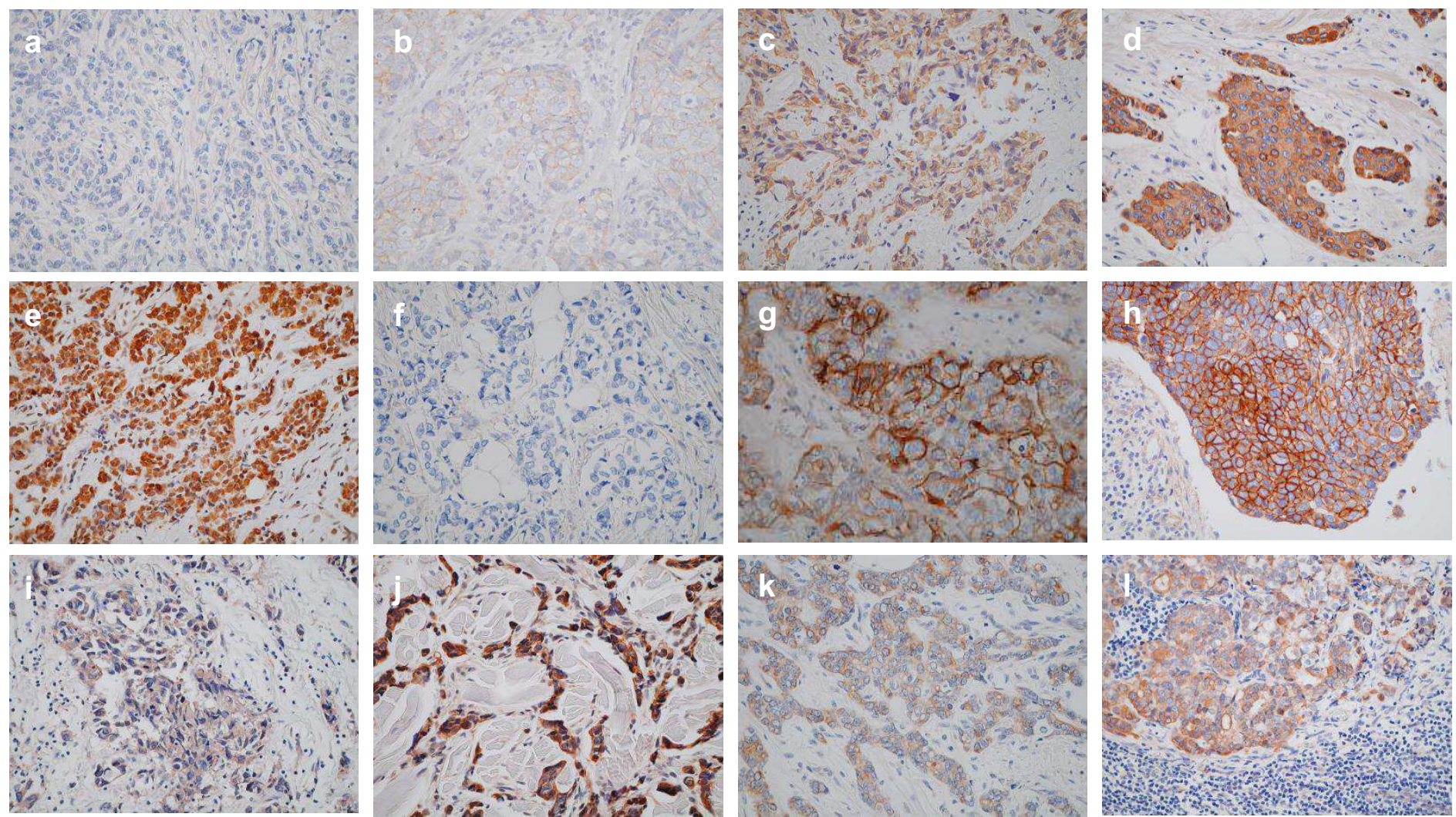
a

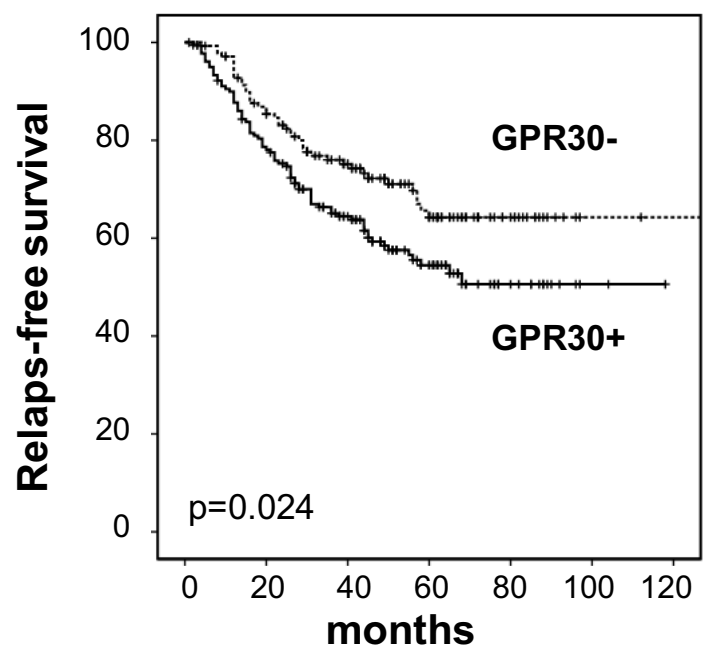

C

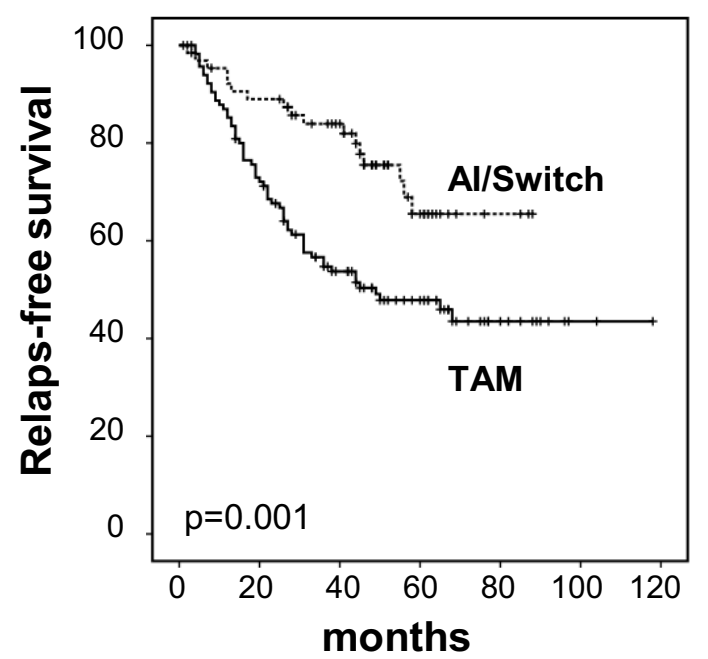

b

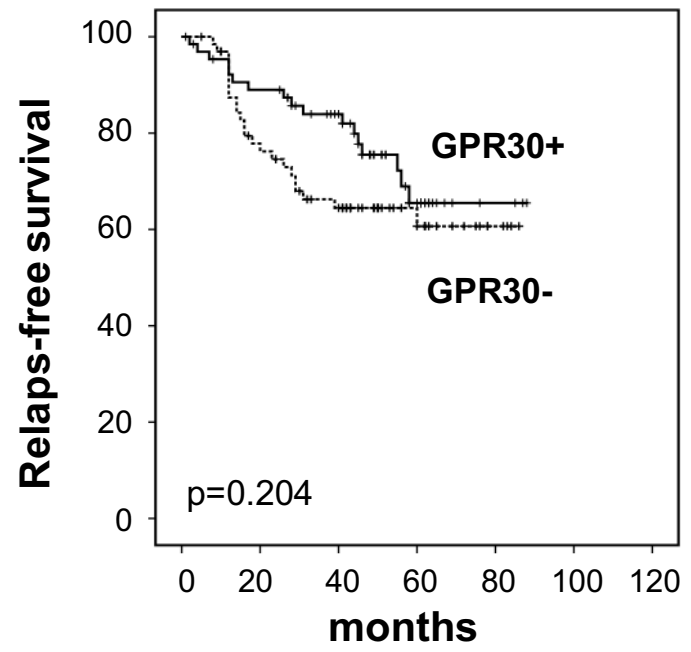

d

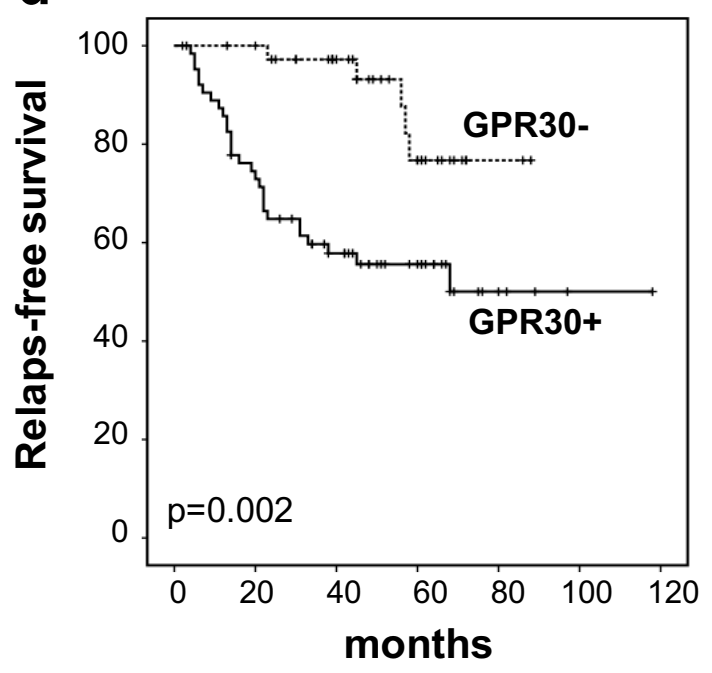


Fiaure ${ }^{3} \boldsymbol{3}_{\text {to }}$ to download Figure: Fig3.ppt
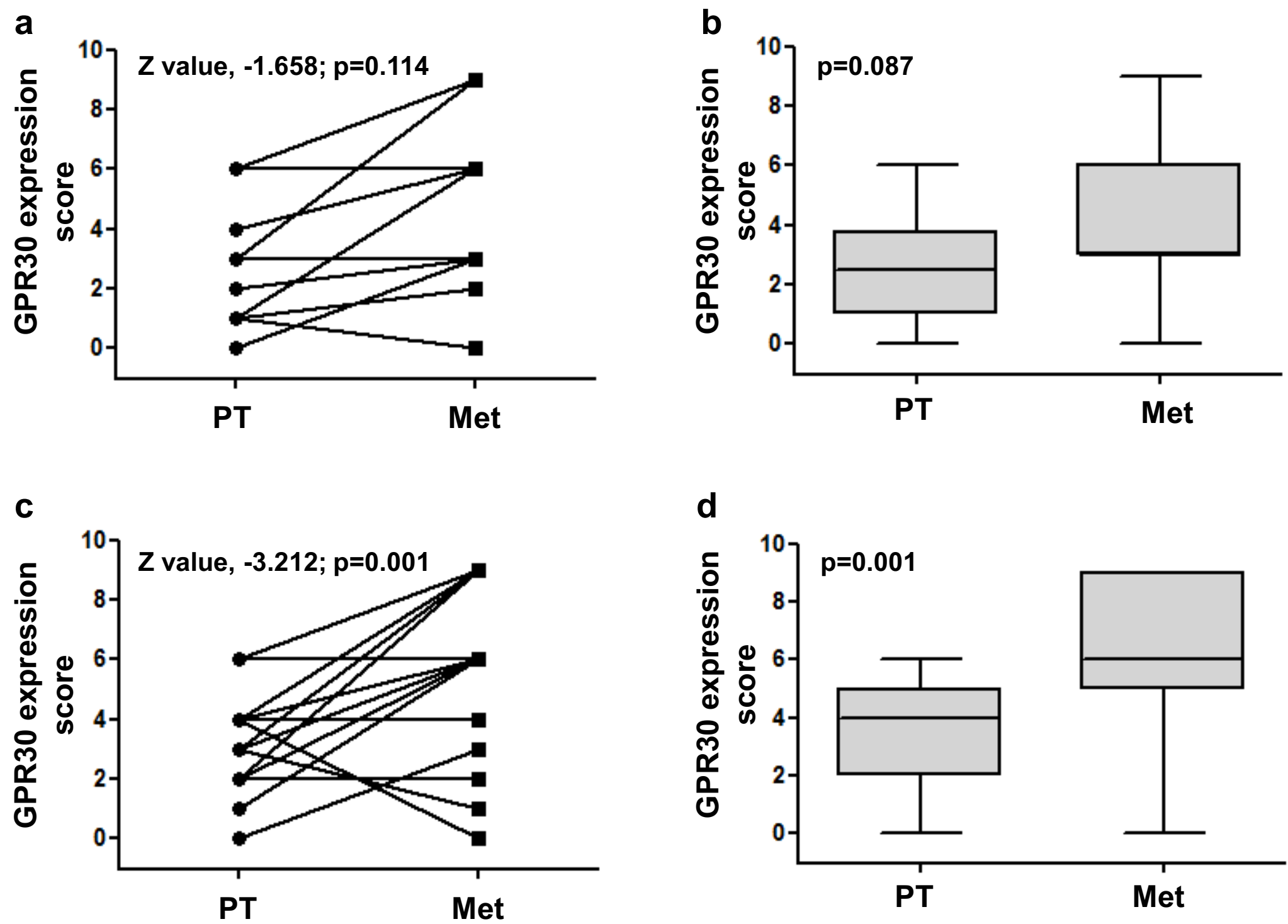